\title{
9 Conclusion
}

It seems that there is no simple, straightforward economic explanation for the United Kingdom's low growth rate since the mid-1950s. The economic system is a complex social phenomenon, and its growth reflects the social, institutional and political factors which underlie the shallower economic transactions summarised in measures of gross national product and output. There is wide agreement amongst economists that increasing factor productivity is much more important in explaining growth than increases in factor input quantities. There is also widespread agreement that the continental European countries have been able to sustain high rates of economic growth over the last twenty years because they were able to redeploy labour away from low productivity (and even peasant) agriculture. Economic analysis is unable however to explain the generation of 'technical progress' (i.e. increasing factor productivity), or to show why the observed redeployment of labour occurred. Examination of the economic factors repeatedly points to the need for consideration of the social, political and institutional factors, and it is clear that the serious student of economic growth needs a broad knowledge of noneconomic matters too.

As illustrated in Chapters 7 and 8, those who have studied economic growth patterns in the Western world are very aware of the need to include less straightforward economic arguments in their analysis. It is necessary to consider difficult questions about the quality of management, the nature of the labour force, the framework of collective bargaining, and underlying social and institutional factors, etc. in order to explain satisfactorily these patterns. Difficult as they may be these questions have to be faced; and their existence only adds to the fascination to be found in the study of growth. This book is no more than an introduction to such study. 